\title{
Fifteen challenges for Service Innovation Studies
}

Faridah Djellal and Faïz Gallouj

\section{Introduction}

In an interesting programmatic article entitled 'Twenty Challenges for Innovation Studies', Ben Martin (2015) lists and discusses the 20 most important challenges he believes 'innovation scholars' will have to address over the coming decades (see Appendix and Box 1A.1). This prospective exercise is based on a review of the 20 major advances made in this field of research since its advent 50 years ago under the name of 'Science Policy Research' (see Box 1.1).

In this contribution, we wish to carry out a similar exercise, this time focusing on services alone. Our aim is therefore to account for the major advances made in 'Service Innovation Studies' (SIS) - and above all to provide an agenda setting out research priorities in this area.

As discussed in Section 1.1 below, services are absent from Ben Martin's list of major advances in Innovation Studies (IS) yet are included in the list of challenges for the future (see Appendix). First, some of the challenges envisaged are horizontal: they concern all economic sectors. Second (though Martin did not explicitly formulate this), others mainly originate in service activities. This is the case, for example, with the 'shift from visible innovation to dark innovation' (see Challenge 1 in the Appendix). Above all, however, the 'shift from innovation in manufacturing to innovation in services' is designated by Martin as one of the most important of the 20 challenges for IS over the coming decades (see Challenge 2 in the Appendix). However, the place accorded to services in the list of major challenges for IS is, in our view, neither sufficient nor satisfactory; it deserves further clarification and extension. A focus on services and the challenges they raise is justified - if only by the centrality of services to contemporary economies. Is it necessary to state that services now account for more than three-quarters of the wealth and jobs in all developed countries, and that emerging and developing countries are no exception to this universal process of tertiarization?

The exercise we intend to carry out in this chapter (and in the book as a whole) suffers, however, from several limitations. First, it is not possible to provide an exhaustive list of challenges; our purpose is merely to identify a sufficient (necessarily arbitrary) number to establish a research agenda and generate debate among 
service innovation scholars (see Box 1.3). Second, it is important to admit that the 'newness' of the identified issues is relative. The absolute novelty is a rarity. In some cases, these issues have already been addressed in the literature, albeit on an ad hoc basis. These issues sometimes concern the exploitation of particular aspects of a major advance (already acknowledged). For example, the cross-fertilization of service innovation and social innovation is a new challenge (Challenge 2 in Box 1.3) and can be interpreted as an enrichment of recognition of the existence of specific forms of service innovation (Advance 3 in Box 1.2). Similarly, the 'Smart Service (Eco) Systems' challenge (Challenge 10 in Box 1.3) could be considered the deepening of the research trajectory, as illustrated by the endogenization of technological innovations (Advance 2 in Box 1.2).

However, the exercise we are suggesting remains of equal interest, for various reasons. First, although it will still be possible for a careful reader to identify an existing reference on a challenge considered new, its inclusion on our list denotes that this is a rich research field whose exploitation is still in its infancy. Such a field constitutes a powerful research trajectory which has yet to reveal all its secrets, and which we must, therefore, continue to explore. Second, regardless of the degree of real novelty (which is arbitrary), as highlighted by Martin (2015), the point and novelty of the proposed exercise is to bring together these different challenges in a single analysis.

As with IS in general, a good way to consider the major challenges in SIS is to begin with a reminder of the main advances made since the establishment of the SIS field. Indeed, the survey of these advances is a useful tool for identifying gaps - and thus potential avenues for further research.

This chapter is broadly organized into five sections. In the first, we outline the 15 main advances achieved in the SIS field over the past two decades, which fall into two distinct but linked groups: on the one hand, advances in theoretical conceptions, and, on the other, advances in innovation modes and institutional arrangements. In the next three sections, we examine the 15 main challenges that could structure our research agendas over the next decade, distinguishing between societal challenges (Section 1.2), organizational and structural challenges (Section 1.3) and methodological and didactic challenges (Section 1.4). Lastly, Section 1.5 is devoted to the conclusion, along with a short presentation of the contents of this book.

\subsection{The main advances made in SIS over the past two decades}

'Science Policy and Innovation Studies' is an area of research that emerged in the late 1950 and whose volume of publications and size of research community have been steadily growing in different fields of social science. On the basis of a thorough bibliometric study of the most cited publications (Martin, 2012), Martin (2015) took stock of the 20 main advances achieved in this field (see Box 1.1). 
Box 1.1 Twenty advances in science policy (Martin, 2015)

1. From individual entrepreneur to corporate innovators

2. From laissez faire to government intervention

3. From two factors of production to three

4. From single division to multidivisional effects

5. From technology adoption to innovation diffusion

6. From science push to demand pull?

7. From single factor to multi-factor explanations of innovation

8. From a static to a dynamic model of innovation

9. From the linear model to an interactive 'chain-link' model

10. From one innovation process to several sector-specific types

11. From neoclassical to evolutionary economics

12. From neoclassical to new growth theory

13. From the optimizing firm to the resource-based view of the firm

14. From individual actors to systems of innovation

15. From market failure to system failure

16. From one to two 'faces' of R\&D

17. From 'Mode 1' to 'Mode 2'

18. From single technology to multi-technology firms

19. From national to multi-level systems of innovation

20. From closed to open innovation

Among these 20 advances, neither 'services' nor 'innovation in services' appears to merit any explicit consideration. It could be argued that, from the innovation in services perspective, these advances are part of what SIS has agreed to call the neglect and assimilation phases/perspectives (Gallouj, 1994, 2010; Coombs and Miles, 2000). Neglect expresses a lack of interest in innovation in services, with the idea that - even if it does exist - the activity is marginal and negligible. Assimilation, however, is an industrialist (and often technologist) analytical perspective that considers there to be no difference between goods and services in terms of innovation, and that the issue of innovation needs to be addressed using existing (industrialist) analytical tools. Such a perspective contributes to the underestimation of innovation in services and (in most cases) to it being limited to the adoption of industrial technical systems.

The rise of SIS has helped challenge this assimilationist (industrialist) perspective by introducing a demarcative (or service-oriented) perspective (Gallouj, 1994, 2010; Coombs and Miles, 200o) focused on the specificities of services, in terms of innovation. This analytical evolution reflects the autonomization of SIS in relation to IS in general, making it possible to identify those advances achieved by SIS in its own right. Box 1.2 provides a list of what we consider the 15 main advances made in SIS since the field's emergence in the second half of the $1980 \mathrm{os}$ and the early 1990 .

This list of advances was drawn up on the basis of the (now relatively numerous) existing reviews of the literature devoted to innovation in services. Our meta-survey 


\section{Box 1.2 Fifteen advances in Service Innovation Studies}

- Advances in the recognition of SIS, in the general theoretical perspectives and the understanding of the nature of innovation

1. From non-innovative services to services as simple adopters of technological innovations

2. From services as simple passive adopters to services as active adopters or even producers of technological innovations

3. From services as adopters/producers of technological innovation to services as producers of specific innovation forms

4. From innovation in some specific service sub-sectors to innovation in all service activities

5. From innovation in services to innovation through services

6. From innovation in services to service innovation (everywhere)

7. From publications in existing journals to the creation of specialized journals

- Advances in innovation operating modes and institutional and regulation arrangements

8. From Oslo Manual 1992 edition to Oslo Manual 2005 edition

9. From assimilation surveys to demarcation and integration surveys

10. From assimilation policies to demarcation and integration policies

11. From the search for productivity to the quest for performance

12. From natural interactivity to linearization and back to a claimed interactivity

13. From services industrialization to goods servitization

14. Balancing the intrinsic tension between service standardization and service customization

15. Balancing the intrinsic tension between service extension and service regression

enabled us to identify no fewer than 20 surveys devoted to innovation in services in general and about 20 surveys specifically addressing one particular sector or theme, over the period 1994-2015 (Gallouj and Djellal, 2015).

Since our project focuses on challenges and avenues for research, we will refrain from detailed discussion here of the 15 advances summarized in Box 1.2, making only the following points:

- These 15 advances are divided into two groups. The first group reflects advances in the recognition of SIS and the theoretical perspectives mobilized. It expresses the transition from the perspective of simple neglect to the perspective of assimilation and demarcation, which we have already mentioned, as well as the evolution towards an inversion perspective (reflecting the active role played by Knowledge Intensive Business Services in their clients' innovation) and integration (favouring a unifying and open concept of innovation for goods and services). In this first group, the advance in the theoretical perspectives favoured also reflects an advance in understanding of the fundamental nature of innovation. The second group of advances, conversely, corresponds to those made in operative modes (structures, processes and innovation strategies) and in institutional and regulatory arrangements (methodological guidelines, survey schemes, public policies, etc.). These advances also fall within the scope of what might be called the neglect-assimilation-demarcation-integration paradigm. 
- Though most of these advances express the transition from one state to another, two (Advances 14 and 15) express the search for a balance between states in tension (between service standardization and customization, on the one hand, and between service extension and regression on the other).

This review of major advances in the field of SIS is a good tool for the identification of gaps and potential research challenges and avenues in this area. We also identified 15 challenges that we propose to discuss here. These challenges can be divided into three groups of unequal size: societal challenges, organizational and structural challenges, methodological and didactic challenges (Box 1.3). Those challenges marked by an asterisk (*) are addressed by one of the chapters of the book. They will be briefly summarized in Section $\mathbf{1 . 5}$.

In formulating these 15 major challenges, we no longer use the 'from . . to' or 'balancing the tension between' formulations used to account for the main advances, preferring to identify general themes that must, in the future, be addressed (or focused on more) by SIS.

It should be observed that taking into account these challenges often brings us back to a fresh reconsideration of some of the previous advances - particularly those involving the definition and measurement of service innovation. It should also be noted that these challenges are not entirely independent of one another; they overlap in certain respects. For example, 'Population Ageing' (Challenge 5) and 'Developing Countries' (Challenge 3) are not independent of 'Social Innovation' (Challenge 2)

Box 1.3 Fifteen challenges for Service Innovation Studies

- Societal challenges

1. Service innovation and the environmental challenge*

2. Service innovation and social innovation*

3. Service innovation and developing/emerging countries*

4. Service innovation and the religious trajectory*

5. Service innovation and population ageing

6. Service innovation and the gender agenda

7. Service innovation and ethical and societal issues

- Organizational and structural challenges

8. Service innovation and entrepreneurship

9. Service innovation, employment and skills

10. Service innovation and smart service (eco) systems*

11. Service innovation, innovation networks and innovation systems

- Methodological and didactic challenges

12. Service innovation in forgotten sectors

13. Service innovation and multidisciplinarity: towards a service science?

14. Service innovation and new evaluation challenges

15. Service innovation studies and service innovation degrees 
insofar as service innovation in developing countries and service innovation in its relationships with ageing are partially based on social innovation. Similarly, the 'New Evaluation Challenges' (Challenge 14) cut across most of the other challenges. Lastly, the challenge concerning the development of Religious Innovation Trajectories (Challenge 4) is linked to the one concerning service innovation in Developing Countries (Challenge 3). After all, many religiously based service innovations (especially in the tourism and finance fields) are implemented in these countries.

\subsection{Societal challenges}

This first group of challenges focuses on innovation in services in relation to certain major contemporary societal challenges: environment, social inclusion, development, religion, ageing, gender and ethical issues.

\section{Challenge 1: service innovation and the environmental challenge}

In a post-industrial and service economy, environmental economics was essentially built in response to damage caused by an intensive industrial and agricultural economy (depletion of non-renewable resources, proliferation of waste, pollution, desertification, deforestation, global warming, etc.). It continues to have strong industrial connotations, though some services (tourism, transportation, etc.) can play an important role in environmental degradation. Thus, as rightly pointed out by Gadrey (2010, p. 94), 'services are ignored by political environmentalism, while environmentalism is neglected by the economics of services' or 'with a few exceptions, the economics of services, as currently constituted, takes little account of environmental or social considerations' (Gadrey, 2010, p. 93). The effects of services on the environment are seldom at the heart of researchers' concerns.

This research gap is even more obvious when it comes to the issue of innovation in services in its relationships with environmental issues. The theoretical (as well as political) challenge represented by these issues is still huge because, as highlighted by Gadrey (2010), the future of the service society will primarily be played out in the ecological field (either positively or negatively) and is closely related to the nature of the innovation trajectories this service society can generate. It is therefore necessary for SIS to address the nature of the ecological impacts of service innovation and discuss the public policies most likely to promote the most positive impacts.

Within this general research agenda, one important hypothesis is worthy of further theoretical and methodological exploration; this is the positive myth ${ }^{1}$ claiming that services are, by nature, environmentally friendly.

\footnotetext{
1 It should be noted that this positive myth contrasts with the many negative myths describing the supposed weaknesses of services: their unproductive nature, low capital intensity and low productivity, low-skill labour, unsuitability to international trade and weak innovation performance (Gallouj, 2002).
} 
This supposedly green nature of services relies mainly on analytical and theoretical arguments. Chief among these is the idea that the immateriality of services makes them, by definition, more environmentally friendly than material goods. For example, some arrangements (or business models) related to the rise of services that have sprung up mechanically in companies, or in society in general, induce a dematerialization - and thence, positive environmental effects. This is illustrated by the goods servitization processes and especially by one of its well-known operative forms, namely the Product-Service System (PSS) (see Advance 13 in Box 1.2). PSSs in their various forms (Product-Oriented, Use-Oriented or Results-Oriented PSS, cf. Tukker, 2004), implemented in order to improve competitiveness, are increasingly analysed as factors of positive environmental externalities. The underlying idea is that adding services or service to goods - or considering goods through their uses, results and the services they provide - contributes to the overall dematerialization of the solution offered to the client, and thus to making the solution greener. The so-called sharing economy or collaborative consumption economy, which favours the shared use of goods (carpooling, car sharing, rental or exchange of personal goods, etc.) and their reuse, as opposed to their private use and disposal, is another illustration of the mechanisms inducing the dematerialization of economic activity.

Some of the theoretical arguments mentioned above in favour of the green nature of services are questionable, including from the theoretical point of view itself. Far from being green by nature, services are more 'material' than they appear. After all, their production requires material resources and energy - indeed, the service transaction is often based on an interaction demanding movement (of persons and goods) that is particularly harmful to the environment (Djellal and Gallouj, 2016; Fourcroy et al., 2012). Moreover, there is no certainty that those environmental benefits generated by increased immateriality are not decreased by the so-called 'rebound effect'. The success of a more eco-friendly service can lead to an increase in its consumption, which may help cancel out the ecological benefit achieved. Even if environmental benefits really are achieved, these are not necessarily reallocated to green practices. ${ }^{2}$ Other undesired effects may occur, which may also strain the ecological benefits of the sharing economy. Environmental benefits achieved through the service innovations of collaborative consumption (especially the extension of product life) can, for example, be a factor in slow technological progress in energy saving. Furthermore, the effectiveness of certain modalities of the sharing economy (such as carpooling) can over time influence public policy, leading to a reduction in efforts to improve public transport.

Though there are theoretical arguments that both justify and call into question the natural sustainability of services and the positive or negative correlation between the rise of service content in the solution provided to the client (as in the PSS,

\footnotetext{
2 For example, savings made by the consumer thanks to carpooling via BlaBlaCar or rental of accommodation via the Airbnb platform can be reallocated to the purchase of a plane ticket to go on holidays - which is not ecofriendly.
} 
for example) and environmental sustainability, such arguments are seldom supported by measurement and evaluation. Research efforts should therefore focus on further theoretical argument, but also - and above all - on measurement and evaluation.

\section{Challenge 2: service innovation and social innovation}

Service Innovation Studies and Social Innovation Studies are two research areas that have developed separately but which resemble each other in many ways:

1) Both have developed on the margins of the dominant academic schools (especially IS) and have struggled to establish their legitimacy. They have nevertheless managed to establish significant research communities, organizing their own regular conferences and publishing their own scientific journals.

2) Construction of their legitimacy was based more on the needs and initiatives of the 'real world' (the socio-economic world: companies, associations, citizens, etc.) than on the academic sphere, and had been supported by government initiatives (national and European funding).

3) Their research object is complex, insofar as it resists the use of existing analytical categories. It is essentially 'human-centred' even though technologies (especially information technologies) play an increasingly important role. Its boundaries are blurred and shifting. This object does not easily lend itself to measurement.

Paradoxically, these two research fields, while similar in many ways, seldom intersect. The cross-references between them are therefore very limited. Conferences organized by one field are seldom attended by scholars from the other. This lack of interaction is partly explained by differing disciplinary backgrounds: sociology for Social Innovation Studies, economics and management for SIS.

However, SIS and Social Innovation Studies are capable of offering one another enrichment in many aspects, and these are worthy of exploration (Djellal and Gallouj, 2012): favoured theoretical perspectives; the nature of innovation, its identification and measurement; modes of organization and ownership regimes; evaluation of its effects; and public policy aimed at fostering innovation. Improved mutual understanding of social innovation and service innovation in the light of each other's insights should help further reduce the hidden or invisible innovation gap in our economies (see Advance 3 in Box 1.2) and allow us to move towards a new and comprehensive innovation paradigm.

\section{Challenge 3: service innovation and developing/emerging countries}

With the exception of some traditional sectors, such as tourism (source of foreign currency) or public administration (source of malfunctions), the services issue has long been absent from research on developing countries. Development economics has also been built on industrial and agricultural models and refer- 
ences. However, although it appeared later than in developed countries, the universal process of tertiarization has not spared the developing countries. For example, as they develop, emerging and transition countries cease being limited to their role as 'the world's factories', also becoming their 'offices and research centres'. After all, in 2014, services accounted for almost 70 per cent of GDP in Brazil, 63 per cent in Russia, 57 per cent in India and 51 per cent in China.

The rise of services in developing countries opens up new fields of research, involving important economic and political issues. The countries concerned by this structural change are aware of this - as illustrated, to some extent, by the creation of research centres on services and the establishment of learned societies in this field. One example is the creation of REDLAS (Latin American Network for Research on Services), which is based on the European Association of Research on Services (RESER) model.

A key question arising in this general framework of services and development is that of innovation in services. This question is largely unexplored. However, it is as strategic for developing countries as it is for developed countries, and researchers will have to give particular consideration to the extent to which this needs to be addressed in different ways - not only in comparison with developed countries, but also for the different types of developing countries concerned (least developed countries, emerging countries, etc.). One of the problems to overcome (especially in order to conduct quantitative studies) is the difficulty of accessing data.

Once again, using the assimilation/demarcation/inversion/integration analytical framework, we are able to formulate a certain number of assumptions (and raise a certain number of questions) that are in need of further exploration.

Taking the assimilation/subordination ${ }^{3}$ perspective, we can formulate the following two hypotheses.

- First, in developing countries, assimilation/subordination is twofold. Services are certainly subordinate to manufacturing (supplier-dominated). But they are also subordinate to the manufacturing industries of the developed countries (North-dominated), since most technological innovations used by services originate in manufacturing companies in Northern countries: computers, trains, boats, aeroplanes, incinerators, scanners and so on.

- Second, as in developed countries, information and communication technologies (ICTs) in developing countries are expected to play an important role in

\footnotetext{
3 It is important to bear in mind that this assimilation/subordination perspective hypothesizes a similarity of innovation in manufacturing and services. This innovation is mainly reduced to technical systems originating from manufacturing firms (which dominate services).
} 
the service innovation issue. Thus, electronic services (e-commerce, e-banking, e-government, etc.) seem to have reached advanced stages of development in some emerging countries (BRIC - Brazil, Russia, India and China), and are much more advanced than SIS in this field. Moreover, ICTs offer many opportunities to Southern economies. They allow some autonomization (vis-à-vis developed economies) of innovation dynamics, as well as the beginnings of a transition from an assimilation to a demarcation perspective in SIS. For example, ICTs are used to produce social innovations targeting inclusive purposes: mobile telephones are the source of many innovative services in the field of mobile banking and micro-finance, as well as m-health (applications allowing the authentication of medicines and the fight against counterfeiting) and m-learning (literacy and access to information).

From the demarcation perspective (i.e. seeking specific forms of innovation that are usually invisible because of their non-technological nature), it can be assumed that developing countries benefit from both a greater degree of freedom and more opportunities for innovation. After all, the innovations highlighted by this perspective have several characteristics that support their emergence in developing economies: 1) they are cheaper than technological innovations, because they do not require significant investment in research and development (R\&D) and patents (frugal innovation); 2) they do not necessarily require complex, institutionalized and permanent structures; 3 ) they may be the result of mere imitations; and 4) they are based on the participation of customers, users or even civil society.

The demarcation perspective applied to services innovation in developing countries is illustrated, for example, by innovation trajectories originating in sustainable development and social innovation issues (see the previous two challenges). Social innovation (which, as pointed out in our discussion of Challenge 2 in Box 1.3, is essentially a service innovation) plays an important role in countries experiencing significant social problems. These innovation trajectories concern all sectors: tourism, finance, retailing, public services and so on. They include, among others, green tourism (aimed at preserving natural, social and cultural heritage), ethical and inclusive finance, fair trade and urban mobility. It should be noted that some of these social innovations (born in Southern economies) are capable of spreading within developed countries.

However, the demarcation perspective also manifests itself through more traditional innovation trajectories, which may be inspired by innovations from developed countries, but are most often different from them because they are adapted to suit local contexts. These include, for example, tourism in its multiple forms (including medical tourism in response to the needs of customers from rich countries); the extremely rapid spread of large-scale retailing in some developing countries (linked to rapid urbanization and the increasing entry of women into the labour market); mobile services and the service innovations these create; and the traditional banking system and financial innovation. 
The inversion perspective, it should be remembered, raises - at micro, meso or macro level - the question of the role of Knowledge Intensive Business Services (KIBS) in the innovation of their industrial or service clients. KIBS are thus essential components of innovation systems. They comprise a knowledge infrastructure that complements that of the state (education and research system). They are most often deficient in Emergent (National) Innovation Systems. As such, they are therefore an interesting research topic, from both the theoretical and the public policy perspectives. The question of how to build and strengthen a KIBS sector in developing countries is a major issue, given the strategic role played by KIBS in growth and innovation. Offshoring of high-value-added services (such as new product development, R\&D projects, Information Technology (IT) development) contributes to the growth of KIBS. Service scholars should devote more attention to these issues.

Finally, as regards the integration perspective, it might be asked whether the developing economies might somehow have invented the functional economy and strategies for extending the life of goods (consideration of the age of the vehicle fleet in some developing countries may provide convincing evidence of this). However, though they are important areas of service innovation, 'services around the product' and 'product-service systems' remain weak in most developing countries. All these issues provide interesting challenges for both research and organizations management.

\section{Challenge 4: service innovation and the religious trajectory}

In contemporary economies, religious dynamics are the source of the (sometimes violent) political upheavals that are regularly reported in the media. However, a more gratifying aspect of these dynamics is at work too: religious dynamics can also underlie innovation dynamics. Religious values can, therefore, be the source of economic values.

This paradoxical convergence between religion (synonymous with conservatism) and innovation (synonymous with change) is an interesting field of investigation, especially (though not exclusively) in developing countries. In the field of services, the religious innovation trajectory is a powerful one with multiple potential areas of application, but it is inadequately addressed by research in service economics and management. Once again, academic research lags way behind the practices of companies and organizations.

This question of the relationship between (service) innovation and religion can be addressed from several different perspectives.

The first (and least interesting, for our purposes) of these is that of the religious mind's ability to innovate. Some studies tend to show a negative correlation between individual and national religiosity and propensity for innovation, while others conclude that innovation is religion-neutral. 
The second perspective reflects an already ancient reality: that which describes religious institutions (in the general sense) as sources of innovation. Throughout history, many social and service innovations have been designed by religious institutions. In Western civilization, examples include orphanages, hospitals, charitable organizations and so on - and, from another perspective, the founding by Christian trade unionism of cooperatives and mutual societies. It should be noted that the religious innovation trajectory has long been closely linked to that of social innovation (see Challenge 2 in Box 1.3).

The third perspective reflects the fact that religious organizations are (at microeconomic level) also service organizations that can (like any other organization) be studied from the innovation perspective. After all, they may provide religious or secular 'clients' (literally or figuratively) with religious or non-religious innovative products or services. They can also innovate within their own processes and organizations. Examples include the online distribution of religious (or monastic) products (Paquier and Morin-Delerm, 2012) as well as using the Internet more generally to build religious community. Works on this topic are however scarce, the main reason being, once again, that innovation and religion are considered mutually exclusive (see also Challenge 12, which is devoted to those service sectors overlooked by SIS).

From an economic point of view, by far the most interesting and promising perspective is that describing the religious factor as a determinant of innovation in private enterprise. This religious innovation trajectory increasingly manifests itself in many sectors, resulting in a great deal of 'religion push' technological innovations and innovative services: watches (or mobile phones) featuring a call to prayer; financial innovations (the flourishing Islamic finance theme renamed and generalized as ethical finance); religious tourist packages; innovations in the hotel business (e.g. Islamic hospitality and especially the so-called Sharia-compliant hotels ${ }^{4}$ ); halal sections in retail stores; and so on. This religious innovation trajectory may face institutional, legal or cultural obstacles of varying significance. These obstacles emerge, for example, in the case of a tourist package involving gender segregation (pool or beach for women only, schedules organized by gender, dress codes for both men and women). They also manifest themselves through the principle of secularism in public services, which, where applied, prohibits certain religious innovations.

\section{Challenge 5: service innovation and population ageing}

Although Ben Martin does not mention the issue of an ageing population and its relationship to innovation in his list of challenges for IS (Martin, 2015; see Appendix), this is nevertheless an important socio-economic and research issue for the future. Indeed, projections from the European Commission (European Commission, 2012) have forecast that, in the European Union, the proportion of

\footnotetext{
4. These hotels (which are even cropping up in some European cities) provide many peripheral services - for example, a prayer mat, a marker (or a compass) to indicate the direction of Mecca, a prayer room, halal food.
} 
seniors (those aged over 65) will reach 30 per cent in 2060 - whereas it was just 17 per cent in 2010. Such a demographic shift will have significant consequences both for the production system as a whole and for how consumer needs are structured. We consider that in a service economy, service innovation has to play an important role in addressing this major societal challenge - that is, to take care of senior citizens and provide them with appropriate services. We must therefore devote sustained research activity to this issue in the future.

Population ageing can take on many facets capable of becoming sources of innovation. The first of these facets is the human resource gap in manufacturing and service companies. This gap (and the declining productivity that can result from it) can be offset by technological innovation efforts in both goods and services (robotics and automation). The second facet is the rise of the so-called silver economy. Senior citizens are, after all, a population whose purchasing power and availability for consumption are above average. Providing them with relevant services and products is an important economic (and hence research) issue. The third facet is the dependency and vulnerability of the elderly, which also constitute a major source of services innovation.

Whatever facet of ageing is considered, the major targets of innovation in services for the elderly that are ripe for exploration by SIS are as follows (Djellal and Gallouj, 2006): 1) forms of assistance and residential provision (institutions, domiciliary services, networks, etc.); 2) technologies (technical systems, architecture and ergonomics, smart housing, care methods, etc.), which may have medical or nonmedical purposes (telehealth vs. telecare); 3) human environment of the elderly, whether family carers or care staff; 4) services provided to the elderly (domestic, care, financial and insurance, leisure, retailing, catering, transportation, etc.).

\section{Challenge 6: service innovation and the gender agenda}

In his 20 challenges for IS (see Appendix), Ben Martin (2015) identifies the need for a shift from 'boy's toys' to 'women's liberation'. He considers IS to have mainly focused on innovations that reflect male interests, what he calls 'boy's toys' (electronics and IT, cars and pharmaceuticals, for example). Thus far they have shown little interest in other (economically and socially important) technological innovations that have to some extent promoted women's liberation: technologies of the domestic sphere, including the refrigerator/freezer, microwave oven, washing powder/detergent, washing machine/tumble drier, vacuum cleaner and so on.

In the services field, too, where the female workforce holds a dominant position in certain activities and sub-sectors, the question of the relationship between service innovation and gender is an important research challenge for the future. This has not been sufficiently explored, although various service characteristics (their focus, in some cases, on the domestic sphere and social issues, their relational nature, etc.) seem to provide fertile ground for the expression of female creativity and innovation. 
The question of service innovation as it relates to the gender agenda can be addressed from at least two different angles: 1 ) the role of service innovation in women's liberation, women's empowerment and gender equality; 2) the role of women as actors in service innovation. In the former case, the liberating power of innovation shifts away from technological innovation (in all its forms) to nontechnological and service innovation, rather than (as in Martin's analysis) from innovation as boy's toys to the technological innovations that supported women's liberation. There is a long list of service innovations that allowed women to escape confinement in the home and join the labour market. These include childcare services, the various types of assistance and residential facilities that provide for the elderly, home delivery and so on. In the latter case, the question of women's place in innovative service entrepreneurship (see also Challenge 8) should also be considered. The research agenda should assess the contribution made by women to both service innovation and innovative entrepreneurship; that is, it should estimate and bridge the 'gender gap' in terms of service innovation and entrepreneurship.

\section{Challenge 7: service innovation and ethical and societal issues}

Service innovation gives rise to a number of ethical and societal questions that are important and interesting research issues for many disciplines: economics, management, sociology, psychology and law, as well as engineering sciences, philosophy and so on. Here we mention just three particularly revealing examples.

The first example concerns the many problems of data security and protection linked to the proliferation of digitized information in some service innovations, particularly in the context of Smart Service Systems (see Challenge 10). Problems arise in the economic sphere: the usual problems of innovation protection. But they also arise in the private sphere. Service innovations relating to what is generically known as 'social media' raise many issues relating to infringement of privacy, trust and confidentiality.

The second example is the loss of freedom caused by the automation of many technology-based service facilities, particularly in the private sphere. This applies, for example, to the automation of all forms of transportation (especially transport by car), which provides a powerful service innovation trajectory for the near future (The National Academies, 2014). This loss of individual freedom is offset by an expected social benefit - namely, increased safety and comfort.

The third example is the manifestation of social opposition to some services innovation. A typical example found in some countries is opposition by taxi drivers to Uber services (private cars with driver). As masterfully theorized by Schumpeter, technological innovations are both destructive and creative. Economic history tells of many events in which workers revolted and broke the innovative machines perceived as destroying their jobs: the silk workers (Canuts) revolt in France, for example, or that of the Luddites in early 19th century England. In the service economy, 
this opposition to innovation manifests itself against new business models and service innovations that challenge incumbent market structures, rather than necessarily against technological innovation as such.

\subsection{Organizational and structural challenges}

The second group of challenges reflects organizational and structural issues. It includes the relationship between service innovation and the following topics: entrepreneurship, employment and skills, and network and/or system dynamics at various levels.

\section{Challenge 8: service innovation and entrepreneurship}

It is indisputable that, in contemporary economies, most company creations (whether innovative or not) are achieved within the service sector. However, scientific works on the relationship between entrepreneurship and service innovation are overly scarce. The effort undertaken within SIS to bridge the innovation gap (see the first six advances discussed in the first section) does not seem to extend to innovative service entrepreneurship. Paradoxically, then, research on this topic is lagging behind. Given the strategic importance of the dynamics of entrepreneurship in our economies, this is a research gap that cries out to be filled. This crucial issue can be addressed alongside certain other general thematics discussed above, namely social innovation (potential source of social entrepreneurship), environmental issues (source of ecological entrepreneurship), the gender agenda (and women's entrepreneurship), the ageing challenge (and what we might term 'silver entrepreneurship', to designate entrepreneurship based on innovations for seniors rather than that initiated by seniors), and so on.

\section{Challenge 9: service innovation, employment and skills}

One of the most prevalent myths about the service society is that it would be 'a society of servants', creating jobs, but only low-skill or 'Mac' jobs (Gallouj, 2002). This myth is easily invalidated by statistical analyses, which show a dual service society, providing both low-skill and high-skill jobs. The service society thus seems to be as much a society of engineers and managers as it is a society of servants.

Works addressing the relationship between services and employment and qualifications are not uncommon, but the same cannot be said of those addressing the relationship between service innovation and employment and qualifications. This is a research topic worthy of further exploration, since it involves significant challenges for the future of companies.

The development of certain service innovations creates job categories and skill types that did not exist before; most of the ICT-related professions that thrive today were not in existence just a few years ago. This applies, for example, to data scientists and social media analysts (The National Academies, 2014). Similarly, 
most of the jobs that will be important in the near future do not yet exist. Overall, the prospective analysis of how service innovation will change the panorama of jobs and skills is a priority for research, business management and public policy.

\section{Challenge 10: service innovation and smart service (eco) systems}

SIS was initially built in opposition to the technologist perspective, which reduces innovation in services to the mere (passive) adoption of technologies by service activities, that is, to the diffusion of industrial innovations in services.

In the practice of companies and organizations, as well as in the work of academics, this concept of a technology that is exogenous to services gives way to a concept that endogenizes technologies in the service transaction or in the service organization. This means that services integrate, incorporate and modify these technologies to adapt them to their own organization and the idiosyncratic nature of their own activities. These technologies are no longer production factors to be analysed through their impacts on productivity and other economic variables (such as in the strictly technologist configuration discussed above); rather, they are hardware components of the product, inseparable from its intangible components. To describe such an incorporation of technology in services, the literature replaces the concept of diffusion with the new concept of technology infusion (Bitner et al., 200o).

The advent of so-called Smart Service Systems (SSS) is a further step, a higher level of complexity in the process of endogenization or incorporation of technology in services. SSS reflect the highest degree of infusion. They combine smart technologies, individuals (customers, producers, citizens, etc.) and organizations that interact to share resources and co-create value. These service systems are 'smart' in that they automatically collect information during service transactions, turning them into knowledge. They are able to learn and transform themselves, using the knowledge gained to adapt the service offered or design new services. SSS are open systems. They are connected to other SSS, from which they can learn and thus transform themselves. Various agents of different sizes are capable of implementing SSS: companies, public administrations and associations.

Social media platforms such as Facebook, Twitter and LinkedIn are SSS. These fast-developing social networks interact in many ways with the economic networks that can rely on them to co-produce service innovation (Uratnik, 2016). The interconnection between social and economic networks (the blurring of boundaries between them) is a research topic in need of further development.

Other systems also belong to this category of SSS: smart vehicles, smart roads (which are integrated into the more general category of smart mobility), smart grids, smart buildings (service systems capable of ensuring better air quality, better energy efficiency, better earthquake safety) and, more broadly, smart cities. All of these systems are in their infancy, representing considerable economic and 
research issues. Thus, within this smart dynamics framework, there is a shift from the smart object to the intelligent infrastructure and then to the smart city. SSS evolution potential is huge: smart region, smart nation, smart planet.

New horizons (and new research perspectives) are open to SSS and service innovation by the so-called Internet of Things (IoT) and Big Data. IoT (which is the third revolution of the internet - Web 3.0) refers to the connection between objects in various fields. It is responsible for the exponential increase in data on the network and therefore for Big Data. Big Data leads to extremely detailed knowledge of the customer and his/her needs and behaviours. It is therefore the source of significant reservoirs of new services and new products. Yet it also raises ethical issues related to data secrecy and privacy protection (see Challenge 7 ).

Up until now, SSS have mainly been envisaged from a practical and descriptive angle. They therefore constitute a clear priority for theoretical and empirical future research.

\section{Challenge 11: service innovation, innovation networks and innovation systems}

One important advance in the field of IS underlined by Ben Martin (2015) is the shift from 'individual actors to systems of innovation' (see Box 1.1). A considerable increase in work on innovation networks and systems can be observed, stimulated by the umbrella concept of 'open innovation'. However, services and service innovation are most often excluded from these works. Indeed, the concepts of innovation networks and systems that have been very successful in both evolutionary economics and the sociology of innovation were designed (from both theoretical and empirical points of view) as industrialist and technologist concepts, as well as organizational arrangements. Although public research (and therefore public services) play an essential role, the key players in innovation networks and systems are manufacturing companies and the form of innovation on which these networks and systems are focused is technological innovation (especially hi-tech). Low-tech sectors and services, which account for the lion's share of our wealth and jobs, are however comparatively absent from network and systemic analysis.

One research priority that began to emerge some time ago, but deserves a special effort, is the question of innovation networks, and systems in which service organizations would occupy a central place (rather than settling for being support agents) and in which the production of non-technological forms of innovation would take its rightful place. The objective is, somehow, to tertiarize the concepts of innovation systems and networks. One can therefore ask, for example, whether the concept of the sectoral innovation system (Malerba, 2002) can be applied to the service sectors. It would also be necessary to pursue the work recently initiated on public-private innovation networks in services (Gallouj et al., 2013). 


\subsection{Methodological and didactic challenges}

The third and final group of challenges is devoted to more epistemological questions. Which new sectors should be envisaged for the pursuit of research on innovation in services? Which research methods should be preferred? What are the new challenges in measurement and evaluation? What are the links between research on innovation in services and education in this field?

\section{Challenge 12: service innovation in forgotten sectors}

As observed in Advance 4, research on innovation is liable to spread across all service sectors. The literature has however focused on particular sectors (KIBS and informational services) before spreading to others (trade, hotels, transportation, etc.). Yet it is worth pointing out that some service sectors continue to be overlooked by SIS. These neglected sectors include religious organizations (see also Challenge 4), prisons, driving schools, hairdressing and other beauty treatments, physical well-being activities, laundry services, funeral services, police, fire services, social housing services, museums, theme parks, non-profit organizations and so on. Low-tech service small and medium-sized enterprises (SMEs) are often among these forgotten sectors. For example, in the case of the hospitality industry, literature exists on innovation in large national and international hotel chains, but not on innovation in boutique hotels (Da Mota Daros, 2017). SIS should establish a systematic list of these forgotten sectors and undertake empirical investigations aimed at understanding their possible innovation dynamics.

\section{Challenge 13: service innovation and multidisciplinarity: towards a service science?}

Given its evolution, and in particular its hybridization with technical systems (IT platforms), the 'service' entity - originally fuzzy and fairly simple (even leading to its being denigrated by economic analysis) - has become a complex object, a 'service (eco) system' linking sophisticated and scalable technical systems with increasingly competent, committed and empowered human actors and multiple organizations (see Challenge 10). If we are to understand the functioning of these 'complex humancentred service systems' (Maglio et al., 2014), then a strictly disciplinary vision is inadequate. It is necessary to mobilize and compare approaches and methods that borrow from different disciplines: economics, management, sociology, psychology, computer science, operations research, industrial engineering and so on.

This is the great ambition of the plea for construction of a 'Service Science' - originally put out by US researchers, but increasingly echoed in Europe (Chesbrough and Spohrer, 2006; Larson, 2008; and Maglio et al., 2010). 'Service Science' seeks to develop a theory of services and service innovation on a fundamentally interdisciplinary basis. Although it accords great importance to IT, it does not fall within the scope of an assimilationist perspective, which would seek to industrialize and materialize an initially immaterial object. Rather, it falls within the scope of an inte- 
grative approach that gives human beings an equally central position in 'complex human-centred services systems'. This linking of the term 'science' with the term 'service' reflects the desire to introduce extra measurement, formalization, systematization, modelling, sustainability, and replication potential to services and their innovation dynamics - though the human component of the system renders this aspiration difficult to achieve. This interesting research programme has already led to the launch of four scientific journals featuring the expression 'Service Science' in their title (Service Science; International Journal of Service Science, Management, Engineering and Technology; International Journal of Services Sciences; Journal of Science Service) and is still in its pre-paradigmatic phase. It is therefore a promising research programme.

\section{Challenge 14: service innovation and new evaluation challenges}

Certain aspects of the innovation gap may have been filled, as we pointed out in Section 1.1, though others remain or are emerging. Thus, whether at the scientific or institutional level (OECD manuals), exploitation of the evaluation challenge is not exhausted. This particularly concerns the following areas: ad hoc and tailor-made innovations, innovation in complex packages, new concepts, new formulas (in retail, hotels, restaurants, etc.), social innovation, innovation in public services, and so on.

These new evaluation challenges are often closely related to some of the major societal challenges listed above. After all, those challenges that raise new measurement and evaluation challenges for all forms of service innovation and service performance are linked to ecological issues, social innovation, developing countries, population ageing and the role of women in service innovation.

One other problem of definition and evaluation remains pending; it concerns research and development. Thus, although the Oslo Manual has been revised several times, and although a new revision is currently under consideration, the same cannot be said of the Frascati Manual, which provides $R \& D$ definitions and indicators. Thus, the latest version of the Frascati Manual (OECD, 2002) remains technology- and science-biased, while $R \& D$ activities in services often have a composite character, mixing aspects of science and technology (S\&T), human and social sciences (H\&SS) and organizational engineering. H\&SS are not sufficiently taken into account, and organizational engineering is not considered at all (Djellal et al., 2003; Miles, 2007).

It should be noted that this evaluation and measurement issue is further complicated by the changing nature of the boundaries between services and goods. Given the changing nature of products, international classifications setting these boundaries are increasingly questionable, and dealing with these issues are research priorities for service studies and SIS (see Broussolle, 2016; Hill, 1999). 


\section{Challenge 15: service innovation studies and service innovation degrees}

The final challenge we are addressing is not, strictly speaking, a research challenge. Rather, it is an educational one - though closely linked to research challenges. Addressed in a recent article by Ferruzca et al. (2016), this challenge raises the question of the ability of SIS to support the creation of specialized lectures or degrees (bachelor's degrees, master's degrees, MBAs) in the field of innovation in services.

Many university degrees in innovation economics and management lean back on IS. To date, to our knowledge, few universities offer specific courses devoted to economics or management of innovation in services, and none offer specialized masters that lean back on SIS. In services-dominated economies, this unlinking of research on service innovation and education in the SIS field is a sign that SIS remains in its infancy. If the academic legitimacy of this research field is to be permanently established, further effort is needed in the educational sphere.

\subsection{Conclusion and content of the book}

SIS is now about a quarter of a century old. Though still marginal in comparison with the well-established field of IS, the body of work is now substantial enough to take stock of progress. Regular literature surveys demonstrate that, in terms of publication volumes, a critical threshold has been reached.

Building on a meta-survey of more than 40 surveys addressing innovation in services (in various ways), we began this work by recalling the major advances achieved in SIS (15 in total). On this basis, we tried to identify key research priorities for SIS in the future (there are also a total of 15 thematic priorities). These priorities can help complement (or enlighten from a fresh angle) the 20 priorities established by Martin (2015) for the broader IS field.

In a relatively new field such as SIS, which has yet to stabilize, the boundaries between acquired knowledge (advances) and knowledge to be developed (challenges, research priorities) are not always clearly drawn. Thus, some of the issues we have included in the 'advances' remain extremely fertile research fields that could easily be integrated to the 'challenges'. We note, for example, that in Gallouj et al. (2015), the 'reconciliation of industrialization and customization of services' and 'the service regression vs. the service extension dynamics' are discussed as 'emerging developments', whereas in this chapter we consider the tensions between the opposing principles described by these dyads as advances in the field of SIS. Conversely, some of the issues we have assigned to the 'challenges' or 'research priorities' category are not necessarily always completely new (a careful reader would certainly be able to point out an existing article addressing the issue in question). Because their exploitation by SIS is still in its infancy, they are still included in the challenges. Furthermore, within certain advances, new fertile avenues for research may appear. For example, while the shift from 'service industrialization to 
goods servitization' is indisputably an advance in research studies (Advance 13 in Box 1.2), it shouldn't contribute to hide a new and promising challenge which is the trend towards 'digital servitization in manufacturing' (Chapter 8).

The eight remaining chapters of this book examine in more depth some of the challenges discussed in this introductory chapter.

Thus, in Chapter 2 ('Services, service innovation and the ecological challenge'), Djellal and Gallouj suggest delving into the myth of green services, arguing that the future of post-industrial economies is also based on the nature of the service innovation trajectories that will be implemented by companies and promoted by public policies. Thus the (analytical and empirical) identification of the various sources of (direct and indirect) materiality in services (too often locked into the ecologically reassuring myth of immateriality) constitutes an important first research path. This must be complemented by a thorough investigation of the various dematerialization strategies implemented in services, as well as more generally throughout the economy.

In Chapter 3 ('Service innovation and social innovation'), Marja Toivonen begins with an overview of the links between service innovation and social innovation. She considers social innovation to be a less well-established field of research than innovation in services, even though this activity is necessary to ensuring equality, inclusion and sustainability in our economies. This chapter highlights two main directions of research to be explored: the first aimed at understanding the fundamental nature of social innovation, and the second concerning the design of appropriate governance structures and innovation policies.

Luis Rubalcaba, Héctor Lagunes and Javier Reynoso devote Chapter 4 ('Service innovation in developing economies') to the research challenges raised by the emerging issue of innovation in services within developing and emerging countries. Their interest is in the role played by innovation as a driving force in services within developing and emerging countries. The research avenues they highlight include the questions of inclusive innovation and innovation for and with the bottom of the pyramid (BoP), that is, for the segment of low-income people, as well as that of the nature of necessary public policies.

Chapters 5 and 6 argue in favour of the ecosystem perspective, seen as a promising framework for the study of innovation in services. In Chapter 5 ('An ecosystem perspective on service innovation'), Bo Edvardsson, Bård Tronvoll and Lars Witell suggest moving forward research on service innovation theoretically by articulating an ecosystem service perspective and a service-dominant logic within a context of value creation. They provide an initial illustration of this theoretical model, using the case of the service ecosystem built around Etalay, a high-end Italian food store chain that includes restaurants, food and beverage stations, bakeries, a bookstore and conference facilities. The authors call for the use of this theoretical construct to understand service innovation in other contexts such as healthcare, the Internet of Things (IoT) and social media, as well as the bottom of the pyramid. 
In Chapter 6 ('Innovation and smart service systems'), Paul P. Maglio and Chiehyeon Lim also suggest the ecosystem perspective as an important element of a research agenda on service innovation. This aims to focus research efforts on the SSS (combinations of intelligent technical systems, information, human actors and multiple organizations) that are set to experience dramatic development in the future. One issue worthy of special attention is the automation of technical systems; how it improves system performance as well as how it can give rise to other system-level innovations. This chapter provides some initial results and avenues for research on the following topics: 1) taxonomies of components of SSS, 2) design principles for effective value co-creation in SSS and 3) the first formulation of a theory of contributions made by technologies to value co-creation. The focus of the chapter is data-use for value creation in SSS.

In Chapter 7 ('Service innovation: towards a religious trajectory'), Camal Gallouj discusses the research perspectives opened up by including consideration of religious dynamics in service innovation. The relationship between religion and innovation can be addressed in various ways and at different levels. Camal Gallouj first discusses the various types of innovation activities (service, organizational, process, social innovations) that are carried out within religious organizations considered as service organizations like others. Then he focuses on how service companies, especially in finance and banking, tourism and retailing rely on the religious determinant to develop new products and services as well as new ways of producing goods and services. Lastly, Camal Gallouj draws up an agenda for future research in the field of religion-related service innovation. This agenda is divided into three research trajectories: 1) a deepening of the existing research paths, 2) a sectoral expansion of the religion-related innovation topic, for example in the field of personal and household services or knowledge intensive services, and 3) the inclusion of new theoretical and managerial issues such as the impact of religion and religiosity on the service relationship and on the process of co-innovation.

The topics addressed in the last two chapters were not included in our list of main challenges. In Chapter 8 ('Digital servitization in manufacturing as a new stream of research: a review and a further research agenda'), Theoni Paschou, Federico Adrodegari, Marco Perona and Nicola Saccani address how digital technologies open up new opportunities for manufacturing firms by adding service value to products, allowing more efficient processes, and supporting improved managerial decisions thanks to richer and faster information. This trend of digital servitization is both a new managerial practice and a new research field within the more established trend of servitization in manufacturing. Chapter 8 provides a review of the scarce literature on the relationships between digitalization and servitization in manufacturing, focusing on how these two megatrends affect resources, competences, skills and business models. It also strives to identify key challenges and to sketch future research directions within this new management and research challenge.

Lastly, Chapter 9 ('New perspectives in public service innovation'), by Annaflavia Bianchi, Giovanni Marin and Antonello Zanfei, focuses on new avenues for research 
in the field of public services. Following the avenues opened up by Djellal et al. (2013), it aims to go beyond the so-called assimilationist perspective to develop a new way of conceptualizing and measuring innovation in public services and, more generally, in 'general-interest services'. This chapter is based on two interlinked streams in the literature: 'public service dominant logic' and 'value creation and co-creation'. It argues that in order to apprehend innovation in public services from a theoretical, empirical and methodological point of view, the following should be addressed: clarification of the identification of the object in question; plurality of the subjects involved in public service innovation; an open innovation perspective; the role of users/beneficiaries; and the variety of public service innovation types and aims.

The number of research priorities selected (15) is obviously arbitrary. It would be possible to add many more challenges in need of SIS attention.

We will settle for briefly mentioning the following challenges here:

- The link between service innovation and economic crisis. As noted by Martin (2015), the financial innovations (identified by him as a challenge for IS) underlying the latest economic crisis have yet to be satisfactorily addressed by IS. Given that financial innovations are service innovations, it is all the more surprising that SIS has neglected their study.

- Service innovation and international trade. It is important to discuss, for example, how service innovation contributes to the growth of international trade in services, and which types of service innovation are most successful in making this contribution.

- Service innovation and public policy. Despite political recognition of the importance of service innovation, political action aimed at fostering service innovation and academic research on these actions still falls a long way short of what is needed.

- Service innovation and geographic issues. The mapping of the geography of service innovation, for example, is largely lacking.

- The customer's new roles in service innovation. Although recognition of the customer's role in the production of services is an old and well-documented phenomenon, new technologies have opened up new avenues of research, leading to consideration of new client roles in service co-creation and innovation.

\section{References}

Bitner, M.J., Brown, S.W. and M.L. Meuter (200o), 'Technology infusion in service encounters', Journal of the Academy of Marketing Science, 28 (1), 138-149.

Broussolle, D. (2016), 'La tertiarisation revisitée dans la perspective des services de Hill, un éclairage sur le cas de l'UE et de la France', European Review of Service Economics and Management, 2016 - 1 (1), 15-64.

Chesbrough, H. and J. Spohrer (2006), 'A research manifesto for services science', Communications of the ACM, 49 (7), 35-40. 
Coombs, R. and I. Miles (200o), 'Innovation, measurement and services: the new problematique', in Metcalfe, J.S. and I. Miles (eds), Innovation Systems in the Service Economy: Measurement and Case Study Analysis, Dordrecht: Kluwer Academic Publishers, pp. 85-103.

Da Mota Daros, M. (2017), 'Innovation and absorptive capacity in low-technology services: boutique hotels in Brazil', PhD Thesis, Maastricht University.

Djellal, F., Francoz, D., Gallouj, C., Gallouj, F. and Y. Jacquin (2003), 'Revising the definition of research and development in the light of the specificities of services', Science and Public Policy, 30 (6), 415-430.

Djellal, F. and F. Gallouj (2006), 'Innovation in care services for the elderly', The Service Industries Journal, 26 (3), 303-327.

Djellal, F. and F. Gallouj (2012), 'Social innovation and service innovation', in Franz, H.-W., Hochgerner, J. and J. Howaldt (eds), Challenge Social Innovation: Potentials for Business, Social Entrepreneurship, Welfare and Civil Society, Berlin: Springer, pp. 119-137.

Djellal, F. and F. Gallouj (2016), 'Service innovation for sustainability: paths for greening through service innovation', in Toivonen, M. (ed.), Service Innovation: Novel Ways of Creating Value in Actor Systems, Springer Japan, pp. 187-215.

Djellal, F., Gallouj, F. and I. Miles (2013), 'Two decades of research on innovation in services: which place for public services?' Structural Change and Economic Dynamics, 27 (December), 98-117.

European Commission (2012), The 2012 Ageing Report: Economic and Budgetary Projections for the 27 EU Member States (2010-2060), Directorate-General for Economic and Financial Affairs, Brussels.

Ferruzca, M., Tossavainen, P.J. and V. Kaartti (2016), 'Educating the future generations of service innovators: insights from Finland', European Review of Service Economics and Management, 2016 - 2 (2), 93-113.

Fourcroy, C., Gallouj, F. and F. Decellas (2012), 'Energy consumption in service industries: challenging the myth of non-materiality', Ecological Economics, 81 (September), 155-164.

Gadrey, J. (2010), 'The environmental crisis and the economics of services: the need for revolution', in Gallouj, F. and F. Djellal (eds), The Handbook of Innovation and Services: A Multidisciplinary Perspective, Cheltenham, UK and Northampton, MA, USA: Edward Elgar Publishing, pp. 93-125.

Gallouj, F. (1994), Economie de l'innovation dans les services, Paris: Editions L'Harmattan, Logiques économiques.

Gallouj, F. (2002), 'Innovation in services and the attendant old and new myths', Journal of SocioEconomics, 31 (2), 137-154.

Gallouj, F. (2010), 'Services innovation: assimilation, differentiation, inversion and integration', in Bidgoli, H. (ed.), The Handbook of Technology Management, Hoboken, NJ: John Wiley \& Sons, pp. 989-1000.

Gallouj, F. and F. Djellal (2015), Services and Innovation, Cheltenham, UK and Northampton, MA, USA: Edward Elgar Publishing.

Gallouj, F., Rubalcaba, L., and P. Windrum (eds) (2013), Public-Private Innovation Networks in Services: The Dynamics of Cooperation in Service Innovation, Cheltenham, UK and Northampton, MA, USA: Edward Elgar Publishing.

Gallouj, F., Weber, M., Stare, M. and L. Rubalcaba (2015), 'The future of the service economy in Europe: a foresight analysis', Technological Forecasting and Social Change, 94 (May), 80-96.

Hill, T.P. (1999), 'Tangibles, intangibles and services: a new taxonomy for the classification of output', Revue canadienne d'économie, 32 (2), 427-446.

Larson, R.C. (2008), 'Service science: at the intersection of management, social, and engineering sciences', IBM Systems Journal, 47 (1), 41-52.

Maglio, P.P., Kieliszewski, C.A. and J.C. Spohrer (2010), Handbook of Service Science, New York: Springer.

Maglio, P.P., Kwan, S.K. and J.C. Spohrer (2014), Workshop to Develop a Research Agenda for Service Innovation, Final Report, National Science Foundation. 
Malerba, F. (2002), 'Sectoral systems of innovation and production', Research Policy, 31 (2), 247-264.

Martin, B.R. (2012), 'The evolution of science policy and innovation studies', Research Policy, 41 (7), 1219-1239.

Martin, B.R. (2015), 'Twenty challenges for innovation studies', SPRU Working Paper Series, SWPS 2015-30, November.

Miles, I. (2007), 'R\&D beyond manufacturing: the strange case of services' R\&D', RED Management, 37 (3), 249-268.

OECD (2002), Frascati Manual, Proposed Standard Practice for Surveys on Research and Experimental Development, Paris: Organisation for Economic Co-operation and Development.

Paquier, M.-C. and S. Morin-Delerm (2012), 'La distribution de produits monastiques par Internet: la nature des dimensions innovantes des sites marchands est-elle contingente de l'ancrage religieux ou laïc des sites?', Management and Avenir, 2012/2 (52), 138-156.

The National Academies (2014), Ideas to Innovation: Workshop to Develop a Research Agenda for Service Innovation.

Tukker, A. (2004), 'Eight types of product-service system: eight ways of sustainability? Experiences from SusProNet', Business Strategy and the Environment, 13 (4), 246-26o.

Uratnik, M. (2016), 'Interactional service innovation with social media users', Service Science, 8 (3), $300-319$. 


\section{Appendix}

Box 1A.1 Twenty challenges for innovation studies (Martin, 2015)

1. From visible innovation to 'dark innovation'

2. From innovation in manufacturing to innovation in services

3. From boy's toys to 'women's liberation'

4. From national and regional to global systems of innovation

5. From innovation for economic productivity to innovation for sustainability ('green innovation')

6. From innovation for economic growth to innovation for sustainable development

7. From risky innovation to socially responsible innovation

8. From innovation for wealth creation to innovation for well-being (or from 'more is better' to 'enough is enough')

9. From 'winner take all' to 'fairness for all'

10. From government as fixer of failures to the entrepreneurial state

11. From fait-based policy (and policy-based evidence) to evidence-based policy?

12. Balancing the intrinsic tensions between intellectual property and open source

13. Balancing the intrinsic tensions between exploration and exploitation

14. Balancing the intrinsic tensions between closed and open innovation

15. Balancing the intrinsic tensions between competition and cooperation

16. Pricking academic bubbles

17. Identifying the causes of the current economic crisis

18. Avoiding disciplinary sclerosis

19. Helping to generate a new paradigm for economics - from Ptolemaic economics to???*

20. Maintaining our research integrity, sense of morality and collegiality

*The question marks are included in the original paper to indicate that the new paradigm after Ptolemaic economics is not known. 